\title{
Ocimum sanctum: Role in Diseases Management Through Modulating Various Biological Activity
}

\author{
Saleh A. Almatroodi' ${ }^{1}$, Mohammed A. Alsahli' ${ }^{1}$ Ahmad Almatroudi ${ }^{1}$, Arshad Husain Rahmani ${ }^{1, *}$
}

Saleh A. Almatroodi', Mohammed A. Alsahli', Ahmad Almatroudi1, Arshad Husain Rahmani ${ }^{1}$ *

Department of Medical Laboratories, College of Applied Medical Sciences, Buraydah 52571, Qassim University, SAUDI ARABIA.

\section{Correspondence}

\section{Arshad Husain Rahmani}

Department of Medical Laboratories, College of Applied Medical Sciences, Buraydah 52571, Qassim University, SAUDI ARABIA.

E-mail: ah.rahmani@qu.edu.sa

History

- Submission Date: 08-05-2020;

- Review completed: 01-06-2020;

- Accepted Date: 01-07-2020.

DOI : 10.5530/pj.2020.12.168

Article Available online http://www.phcogj.com/v12/i5

\section{Copyright}

(C) 2020 Phcogj.Com. This is an openaccess article distributed under the terms of the Creative Commons Attribution 4.0 International license.

\section{ABSTRACT}

Medicinal plants are used commonly by traditional medical practitioners in their daily practice for the treatment of various diseases. The treatment based on natural products are preferred because they are more economic and have lesser side-effects. In this regards, Ocimum sanctum commonly known as holy basil or tulsi is used in the diseases cure and treatment since ancient time. Ocimum sanctum has been proven health promoting effect through modulation of various biological activates. Ocimum sanctum shows therapeutic role through its anti-oxidant, anti-inflammatory, anti-microbial, anti-diabetic, hepatoprotective and wound healing effects. Besides, the constituents of holy basil have been confirmed to have a noteworthy effect in cancer management through inhibition of cancer development and progression. Further, the synergistic effect of Ocimum sanctum component with anti-cancer drugs has been proven as it reduces the growth of cancer. Molecular mechanism and human clinical trials based should be performed to avail its role in diseases cure and management. This review comprehensively summarizes the role of holy basil in disease management through in vivo and in vitro study. Key words: Ocimum sanctum, Health promoting effect, Anti-cancer, Anti-oxidant effect.

\section{INTRODUCTION}

Medicinal plants are commonly used by traditional medical practitioners in their daily practice for the treatment and prevention of various diseases. The treatment based on natural products have advantage over allopath based treatment due to its reduced expensiveness and lesser side effects. In modern complementary and alternative medical practice, plants are the chief source of therapeutics and various parts of the plant, such as seeds, root, stem, leaves, as well as fruit holds various types of bioactive components ${ }^{1-3}$ and these bioactive play a significant role in the diseases cure and prevention. Curcumin of turmeric, thymoquinone from black seed, oleuropein of olive, gingerol and shogaol of ginger and various other active compounds shows therapeutic role via modulating biological activities and kills various types of cancer cells.

Lamiaceae is a family of many medicinally important plants which are used for curative and preventive purposes for various disorders. Basically, 236 genera and more than 6000 species belong to this family. The largest genera of Lamiaceae family include Salvia, Scutelleria, Stachys, Plectranthus, Hyptis, Teucrium, Vitex, Thymus, Nepeta. ${ }^{4}$ The therapeutic potential of plants belonging to these genera is attributed to the presence of a wide range of phytochemicals like alkaloids, saponins, flavonoids, polyphenolic contents. Many researchers have reported the several bioactive potentials of different genera of Lamiaceae shows biological activities such as antioxidant, antimicrobial, antiinflammatory, antidiabetic, cardioprotective effects etc. ${ }^{4}$ Genus Ocimum contains more than 150 species including Ocimum tenuiflorum L. (holy basil), Ocimum gratissimum (African basil), Ocimum basillicum (sweet basil), Ocimumam mericanum. The plants of this genera have been recognized to possess several medicinally important bioactivities such as antifungal, antinocicepative, anticonvulsant, antioxidant, germicidal and antimalarial activities, etc. ${ }^{5}$ These species belonging to Genus Ocimum have excellent therapeutic potentials and medicinal properties. Ocimum tenuiflorum, is normally known as holy basil or tulsi (Figure 1).

The following is the classification of Tulsi ${ }^{6}$

Kingdom: Plantae

Order: Lamiales

Family: Lamiaceae

Genus: Ocimum

Species: tenuiflorum

Therapeutic roles of Tulsi have been noted since ancient time. Tulsi is used in various forms and it is taken as herbal tea, dried power or fresh leaf and the dried leaves of tulsi are used to be mixed with stored grains to prevent insects. ${ }^{7}$ Various types of active compounds have been reported to be found in Tulsi. These bioactive compounds show role in the disease management through modulation of various biochemical and physiological processes. Antioxidant activity has been explained as aqueous extract increased antioxidant enzymes superoxide dismutase, catalase, glutathione peroxidase, as well as glutathione transferase. ${ }^{8}$

Tulsi has been found to be a chief source of many biologically active compounds like Ursolic acid, Eugenol, Rosmarinic acid, Linalool, Carvacrol, and

Cite this article: Almatroodi SA, Alsahli MA, Almatroudi A, Rahmani AH. Ocimum sanctum: Role in Diseases Management Through Modulating Various Biological Activity. Pharmacogn J. 2020;12(5):1198-205. 
$\beta$ caryophyllene. The chemical structure of active compound is given below (Figure 2). Various kinds of essential oils have been prepared from Tulsi. The oils obtained from Tulsi have been reported to inhibit the growth of bacteria. Various compounds have been identified in Tulsi leaves, flower spikes, or essential oil and all of these three are anticipated to be accountable for such activity are camphor, eucalyptol and eugenol. ${ }^{9}$ The role of tulsi in cancer inhibition has been proven as given of aqueous and ethanolic extracts of Ocimum sanctum to mice bearing Sarcoma-180 solid tumors arbitrated an important reduction in tumor volume and an increase in lifespan and this finding evidently designate Ocimum sanctum extracts hold anticancer activity. ${ }^{10}$ This review comprehensively summarizes the role of Tulsi in various types of disease management through modulating various biological activities, along with special emphasis on in vivo and in vitro study.

\section{Mechanism of action of Ocimum sanctum}

Tulsi holds various ingredients in the different parts of plants and stem as well as leaves hold a variety of constituents such as saponins, triterpenoids, flavonoids, and tannins ${ }^{11}$ and leaf volatile oil contains eugenol. ${ }^{12}$ These constituents show pivotal role in disease cure and diseases management through modulating various biological activities. The possible mechanisms of action of Tulsi in health management are described as below;

Higher concentration of reactive oxygen species generates oxidative stress and damage to the macromolecules and cause the pathogenesis. Antioxidant activity of medicinal plants neutralise the free radical potentiality and act as a scavenger of free radical. Medicinal plant inhibits the pathogenesis through neutralisation of oxidative stress via antioxidant property. Free radical scavenging activity is a chief mechanism through which Ocimum sanctum products protect against cellular damage. ${ }^{13}$ Its role in free radicals scavenging property has confirmed it has strong antioxidant activity and free radicals scavenging property respectively. Additional, hydrogen peroxide, hydroxyl radical and superoxide radical scavenging methods determined that extracts with concentration $100 \mu \mathrm{g} / \mathrm{ml}$ have hydrogen peroxide (20.12\%),
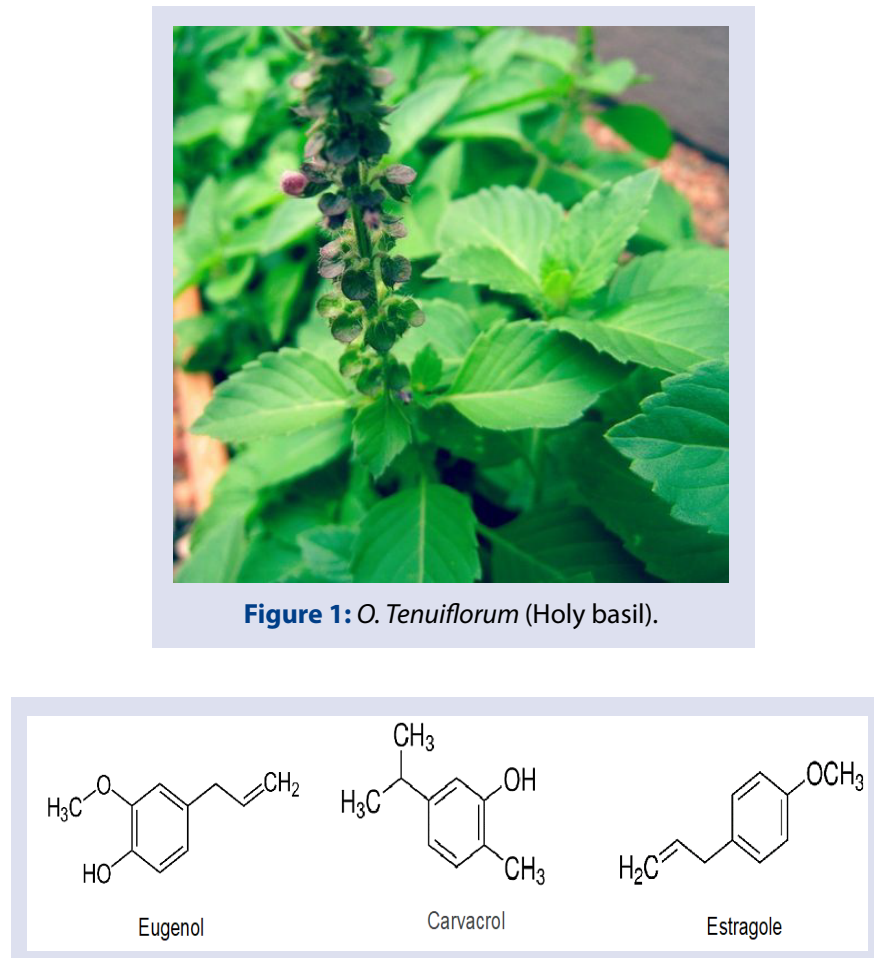

Figure 2: Chemical structure of active compound of Holy basil. hydroxyl radicals (12.68\%) and superoxide radicals (21.68\%) scavenging activity respectively. ${ }^{14}$

Several diseases like cancer, diabetes etc. have been reported to be linked with inflammatory processes. Tulsi, may help to reduce inflammation and act as anti-inflammatory agents through modulating activities of various genes. Ocimum sanctum essential oil at concentration $250 \mu \mathrm{g} /$ $\mathrm{mL}$ and more decreased MMP-9 activity in lipopolysaccharide induced inflammatory cells and dose-dependent downregulation of MMP-9 expression was seen with the treatment of Ocimum sanctum essential oil compared to the control. ${ }^{15}$ Alcoholic and water extracts of OS-dry leaves (OSAE and OSWE) $(1 \mathrm{mg} \mathrm{dwt} / \mathrm{mL})$ pure compound EUG $(60 \mu \mathrm{g} / \mathrm{mL})$ and positive control IMT $(20 \mu \mathrm{g} / \mathrm{mL})$ showed marked inhibition on LPS induced TNF- $\alpha$ secretion by THP- 1 cells. At the selected concentration, the plant extracts, EUG and IMT inhibited gene expression of cytokines and chemokines and translocation of NF- $\mathrm{kB}-\mathrm{p} 65$ to the nuclei. ${ }^{16}$

Resistance to antibiotic drugs is major health problem and its remedy is urgently needed. Natural compound plays a significant role in the inhibition of bacterial growth or kill the bacteria through rupture of cell wall. Tulsi has established anti-gonorrheal efficacy against multiresistant strains of Neisseria gonorrhoea and clinical isolates of beta-lactamase producing methicillin resistant Staphylococcus aureus. ${ }^{17}$

Holy basil plays significant role as anti-tumour through its activity against cancer cells or inhibit the cancer cells. Moreover, anti-tumour effect of holy basil was noted through modulating cell signalling pathways. Extracts of holy basil leaves inhibit the proliferation, migration, invasion, and also play role in the induction of apoptosis of pancreatic cancer cells. The expression of genes that promote the proliferation, migration and invasion of pancreatic cancer cells such as activated ERK-1/2, FAK, and p65 was downregulated in pancreatic cancer cells after O. sanctum treatment. ${ }^{18}$

\section{Pharmacological effects of holy basil}

\section{Antioxidant effect}

A pioneer study was performed to examine whether Ocimum sanctum protects against radiation induced lipid peroxidation in liver and this study was aimedto determine the role of the inherent antioxidant system by extract. The result showed that extract of $O$. sanctum (OE) increased the important antioxidant molecule i.e., glutathione (GSH) and other antioxidant enzymes significantly above normal levels whereas radiation significantly reduced all the values. Further, pretreatment with the extract checked the radiation induced depletion of GSH and all of the antioxidant enzymes and maintained their levels within or above the control range. Study based on finding concluded that Ocimum extract (OE) protects against radiation induced lipid peroxidation and that protecta the reduction of GSH and other antioxidant enzymes. Thus, Ocimum have a significant role in the protection from oxidative damage induced by oxidative stress. ${ }^{19}$ The antioxidant activity of holy basil and herbal powder was examined in rats with liver injury caused by administration of carbon tetrachloride mixed witholive oil. Holy basil and herbal powder was given orally and it exhibited statistically significant antioxidant activity, reported by increased levels of glutathione peroxidase, glutathione S-transferase, glutathione reductase, superoxide dismutase and catalase. ${ }^{20}$

A previous study was performed to evaluate the potential role of alcoholic and aqueous extracts of Ocimum sanctum in wound healing. The Result demonstrated that alcoholic and aqueous extract significantly increased wound breaking strength and antioxidant levels including superoxide dismutase, catalase, reduced glutathione. In addition, lipid peroxidation was found to be significantly decreased the when compared with the control group. ${ }^{21}$ 
The result of another study havereported that radiation significantly increased the lipid peroxidation rate. However, pretreatment with Ocimum extract (OE) meaningfully reduced the lipid peroxidation and enhanced recovery to normal levels. The findings detailed that Ocimum extract protects against radiation induced lipid peroxidation and that GSH and the antioxidant enzymes seem to have a significant role in the protection. $^{19}$

\section{Anti-inflammatory activity}

The essential oil of Ocimum sanctum at the concentration of 250 $\mu \mathrm{gram} / \mathrm{mL}$ and more concentration have been showed a significant decrease in the number of migrated cancer cells and suppressed Matrix metallopeptidase 9 (MM9) activity in lipopolysaccharide induced inflammatory cells. Moreover, a dose-dependent downregulation of Matrix metallopeptidase 9 expression was seen with the treatment of Ocimum sanctum essential oil. The finding revealed that Ocimum sanctum essential oil possessed antimetastatic and anti-inflammatory potentials. ${ }^{22}$

In a recent study, the fixed oil of Ocimum sanctum was established to determine its significant anti-inflammatory activity against carrageenan and several other mediator-induced paw edema. Further, a substantial inhibitory effect was also seen in castor oil-induced diarrhoea. It also inhibited arachidonic acid and leukotriene-induced paw edema and results of anti-inflammatory activity of Ocimum sanctum support the dual inhibition of arachidonate metabolism as designated through its activity in inflammation models that are insensitive to selective cyclooxygenase inhibitors. ${ }^{23}$

The result of an in vivo study demonstrated that newly synthesised NLCs formulation of Ocimum sanctum L. leaf extract showed brilliant anti-arthritic activity and the results were found to be comparable with standard drug diclofenac gel for its analgesic and anti-arthritic activities. $^{24}$

Another study result demonstrated that essential oil extract of holy basil caused antibacterial efficacy, which improved with an increase in concentration as well as contact period. Moreover, it also showed a significant anti- inflammatory action. ${ }^{25} \mathrm{~A}$ methanol extract and an aqueous suspension of holy basil were found to inhibit acute as well as chronic inflammation tested by carrageenan-induced pedal edema and croton oil-induced granuloma and exudate, respectively. In both test procedures, the anti-inflammatory response of $500 \mathrm{mg}$ per $\mathrm{kg}$ of methanol extract and aqueous suspension was comparable to the response observed with $300 \mathrm{mg}$ per $\mathrm{kg}$ of sodium salicylate. ${ }^{26}$

Another interesting finding based on the role of holy basil as antiinflammatory revealed that Ocimum sanctum fixed oil and linolenic acid possessed significant antiinflammatory activity against PGE2, leukotriene and arachidonic acid-induced paw edema. Moreover, finding advocate that linolenic acid present in O. sanctum fixed oil has the capability to stop both the cyclooxygenase and lipoxygenase pathways of arachidonate metabolism and might be accountable for the anti-inflammatory activity of the oil. ${ }^{27}$

\section{Anti-microbial effects}

The antiviral efficacy of three different extracts each from leaves of $O$. sanctum was tested against $\mathrm{H} 9 \mathrm{~N} 2$ virus. The result demonstrated that all thre extracts of $O$. sanctum had significant virucidal activity. Likewise, therapeutic effect was seen in all three extracts of $O$. sanctum in comparison to the virus control, nevertheless, crude extract of Ocimum and terpenoid of Ocimum maintained this effect for longer period of time. ${ }^{28}$ Another study was performed to examine the antimicrobial activity of Ocimum sanctum (tulsi) extract. The result revealed that $8 \%$ concentration of the tulsi extract showed maximum zone of inhibition against A. actinomycetemcomitans and $P$. gingivalis. Moreover, antimicrobial activity of tulsi extract at 6 and $8 \%$ concentrations, and $0.2 \%$ chlorhexidine against $A$. actinomycetemcomitanshowed statistically significant differences between the groups. It was established that $8 \%$ concentration of $O$. sanctum (tulsi) extract showed the maximum antimicrobial activity against $A$. actinomycetemcomitans and $P$. gingivalis. ${ }^{29}$

An interesting study was performed to measure the in vitro antimicrobial activity of Tulsi leaves extract on periodontal pathogens. Result confirmed that at $5 \%$ and $10 \%$ concentrations, Tulsi extracts established antimicrobial activity against A. actinomycetemcomitans, similar to doxycycline with similar inhibition zones. Moreover, study based on finding established that tulsi demonstrated effective antimicrobial property against A. actinomycetemcomitans, advising its probable use as an in effect and reasonable "adjunct" along with the standard care in the managing of periodontal conditions. ${ }^{30}$

Anti-microbial activity (Minimum Inhibitory Concentration and zone of inhibition) of holy basil extract against Actinobacillus actinomycetemcomitans in human dental plaque was evaluated. Result of the study confirmed that at the $6 \%(\mathrm{w} / \mathrm{v})$ concentration of holy basil extract, a zone of inhibition of $22 \mathrm{~mm}$ was obtained and it was the widest zone of inhibition observed among all the ten different concentrations tested. The zone of inhibition for positive control was $25 \mathrm{~mm}$ and no zone of inhibition was observed around the negative control. ${ }^{31}$

Antifungal activity of Ocimum sanctum leaves against dermatophytic fungi was measured. The result of the study demonstrated that $O$. sanctum leaves possessed antifungal activity against clinically isolated dermatophytes at the concentration of $200 \mu \mathrm{g} / \mathrm{mL}$. Based on the finding of this study, it was concluded that Ocimum sanctum had antifungal activity, and the leaf extracts might be a useful source for dermatophytic infections. $^{32}$

\section{Anti-diabetic effect}

A study was performed to isolate and characterize antidiabetic component from hydro alcoholic extract of Ocimum sanctum aerial part. The result revealed that bioactive fraction was potent antidiabetic because of its potential to improve glucose as well as lipid parameters. The finding advocate that tetracyclic triterpenoid isolated from aerial part of Ocimum sanctum has a pronounced anti-diabetic potential. ${ }^{33}$ The silver nanoparticles derived from O. sanctum and O. basilicum, correspondingly showed an inhibitory effect at $89.31 \pm 5.32 \%$, and 79.74 $\pm 9.51 \%$, respectively, against Bacillus stearothermophilus a-glucosidase enzyme model who demonstrates an improved biocatalytic potential compared to their respective crude extracts and the control. ${ }^{34}$

A pioneer study explained the effects of the fixed oil extracted from holy basil leaves on the blood glucose levels and serum lipid profile of streptozotocin-induced diabetic rats. The results demonstrated that fixed oil significantly decreased the elevated levels of blood glucose, the serum lipid profile and the levels of serum creatinine. Additionally, the fixed oil increased the diabetically-reduced levels of serum insulin as well as decreased the kidney weight. Besides, fixed oil decreased the elevated thiobarbituric acid reactive substances level and increased the activity of various anti-oxidative enzymes in the rat renal tissue..$^{35}$

Another study was performed to measure the effect of $O$. santalum on three important enzymes of carbohydrate metabolism, hexokinase and phosphofructokinase along with glycogen content of insulindependent and insulin-independent tissue. Administration of extract at dose of $200 \mathrm{mg}$ per kg causes decrease in plasma glucose levels. Renal glycogen content increased by over ten folds while hepatic and skeletal muscle glycogen content decreased by 75 and $68 \%$ in diabetic controls versus controls. $^{36}$ 
Oral administration of alcoholic extract of leaves of holy basil led to noticeable dropping of blood sugar level in normal, glucose fed hyperglycemic and streptozotocin induced diabetic rats. Additionally, the extract potentiated the action of exogenous insulin in normal rats. ${ }^{37}$

\section{Hepatoprotective effect}

A recent study was conducted to determine the hepatoprotective activity of holy basil and its combination with silymarin and to examine whether its synergistic hepatoprotection exists with silymarin. The results based on this study confirmed that Ocimum sanctum alcoholic leaf extract shows important hepatoprotective activity and synergism with silymarin. ${ }^{38}$ Hepatoprotective potency of holy basil aqueous extract against butyl p-hydroxybenzoic acid toxicity in mice was examined. The result demonstrated that oral treatment of butylparaben to mice resulted in significant elevation in hepatic lipid peroxidation, which could be due to significant reduction in non-enzymatic antioxidant contents and enzymatic antioxidants activities. Co-treatment of holy basil extracts in different doses resulted in significant reduction in butylparaben-induced hepatic changes. Oral administration of $O$. sanctum with butylparaben resulted in dose-dependent and significant reduction in lipid peroxidation as compared to butylparaben alone treated group..$^{39}$

\section{Anti-ulcer effect}

It was reported that Ocimum sanctum, decreased the incidence of ulcers and also enhanced the healing of ulcers. Moreover, holy basil completely healed the ulcers within twenty days of treatment in acetic acid-induced model. It was seen that that anti-ulcer effect of holy basil may be due to its cytoprotective effect. ${ }^{40}$ The antiulcerogenic property of holy basil was examined in pyloric ligated and pyloric ligated and aspirin treated rats. The extract of holy basil reduced the ulcer index, free and total acidity on acute and chronic administration. After seven days of pretreatment with the drug increased the mucous secretion also. Finding advoc that extract has antiulcerogenic property against experimental ulcers, and it is due to its ability to reduce acid secretion and increase mucous secretion..$^{41}$

\section{Anti-fertility effect}

Anti-fertility effect of holy basil was investigated and it was noticed that treatment of rats with a leaves extract with dose of $250 \mathrm{mg} / \mathrm{kg}$ body weight decreased total sperm count and sperm motility. Moreover, percentage of abnormal sperm increased in caudal epididymal fluid, and the fructose content decreased in the caudal plasma of the epididymis. Study based on finding revealed that this effects are due to androgen deprivation, caused by the anti-androgenic property of holy

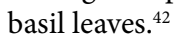

\section{Anti-stress effect}

Anti-stress potential of holy basil in chronic variable stress paradigm and mechanism of anti-stress was explored in vitro using cell and cellfree assays was examined. Rats were given Ocimum sanctum followed by chronic variable stress regimen. Ocimum sanctum and its constituents inhibited cortisol release. Therefore, Ocimum sanctum was found to be effective in the management of stress effects, and anti-stress activity could be due to inhibition of cortisol release as well as blocking CRHR1 receptor. $^{43}$

\section{Anti-amnesic effect}

A study was conducted to investigate the anti-amnesic effect of various Ocimum Species extracts using in-vitro and in-vivo models. Significant antioxidant and acetylcholinesterase (AChE) inhibition activity was observed with all prepared extracts. The in-vivo studies showed that O. basilicum extract (OBE) pre-treatment reversed the memory deficit induced by scopolamine in mice, evident by significant decrease in the transfer latency time and increase in step down latency in elevated plus maze and passive shock avoidance task, respectively. ${ }^{44}$

\section{Effect on nervous system}

The effect of Ocimum sanctum leaf extract on the dietary supplementation in the parkinson's disease was investigated. Result demonstrated that supplementation of holy basil extract showed a dose dependent significant delay in the loss of climbing ability and reduction in oxidative stress in the brain of parkinson's disease model flies. Finding concluded that holy basil extract is powerful in reducing the parkinson's disease symptoms. ${ }^{45}$ The ethanolic extract from the leaves of Ocimum sanctum was screened for its effects on the noise induced changes in the central cholinergic system. Result confirmed that pretreatment of the animals with ethanol extract of holy basil leaves prevented the noise induced changes in two cholinergic parameters in all areas of brain. The results of the study designate the protective nature of the plant material on the brain tissues against the detrimental effect of noise stress. ${ }^{46}$

\section{Immunomodulatory effect}

Immunotherapeutic potential of aqueous extract of holy basil leaf in bovine sub-clinical mastitis was examined. The results demonstrated that the aqueous extract treatment reduced the total bacterial count and increased neutrophil and lymphocyte counts with enhanced phagocytic activity. ${ }^{47} \mathrm{~A}$ methanol extract and an aqueous suspension of holy basil leaves were investigated for their immunoregulatory profile. The results of the study demonstrated an immunostimulant capability for holy basil which may be related in clarifying the adaptogenic action of the plant ${ }^{26}$ The result of another study demonstrated that significant increase in the levels of IFN- $\gamma$, IL- 4 and percentages of T-helper cells and NK-cells were observed in the Tulsi extract intervention group in contrast to the placebo group. ${ }^{48}$

Another study investigated the effect of seed oil on some immunological parameters. Seed oil caused a significant increase in anti-sheep red blood cells antibody titre and a decrease in percentage histamine release, and decrease in footpad thickness and percentage leucocyte migration inhibition. Therefore, seed oil seems to modulate both humoral and cell-mediated immune responsiveness. ${ }^{49}$

\section{Hypolipidemic effect}

A study result confirmed that fresh leaves of Tulsi were mixed as $1 \mathrm{~g}$ and $2 \mathrm{~g}$ in 100 grams of diet given whoconveyed about noteworthy changes in the lipid profile of normal albino rabbits. Moreover, it resulted in significant lowering in serum total cholesterol, phospholipid, triglyceride and significant increase in the HDL-cholesterol and total faecal sterol contents..$^{50}$

Another study result concluded that treatment with fixed oil during the last three weeks of high fat fed-diet diet feeding decreased the high serum lipid profile and cardioprotective actions against hyperlipidemia. The anti-hyperlipidemic action of holy basil fixed oil was chiefly resulted from the suppression of liver lipid synthesis. Linolenic acid and linoleic acid confined in holy basil fixed oil were probably accountable for both lipid-lowering and cardiac protective action against hyperlipidemia. ${ }^{51}$

\section{Cardioprotective effect}

An experiment was performed to search any beneficial effect of holy basil in experimental pulmonary hypertension in rats. Result confirmed that Ocimum sanctum at a dose of $200 \mathrm{mg}$ per kg treatment improved increased lung weight to body weight ratio and right ventricular hypertrophy. Furthermore, Ocimum sanctum treatment was found to decrease Nox-1 expression and increased the expression of Bcl2/ Bax ratio. The study validates that Ocimum sanctum has therapeutic 
capability against pulmonary hypertension in rat which are attributed to its antioxidant effect. ${ }^{52}$

The effect of methanolic extract of Tulsi leaves on inflammation in isoproterenol induced myocardial infarction in rats was examined. Isoproterenol induced myocardial infarction and increased the levels of cardiac markers and phospholipid content.

Though, the same were reduced on pre-treatment with extract of holy basil leaves. The activities of 5-lipoxygenase and cycloxygenase-2 and levels of leukotriene B4 and thromboxane B2 were also elevated in isoproterenol -treated rats, which were significantly decreased in extract pre-treated rats. Study based on result demonstrated that cardioprotective effect may be due to the high phenolic content of methanolic extract of leaves. ${ }^{53}$

\section{Wound healing effect}

A study was performed to evaluate the wound healing effect and it was demonstrated that extract of holy basil meaningfully increased the wound breaking strength in incision wound model. The extract treated wounds were found to epithelialize faster and the rate of wound contraction was significantly increased as compared to control wounds. Finding revealed that the leaf extract promotes wound healing considerably and capable to overcome the wound healing suppressing action of dexamethasone. ${ }^{54}$ The measurement of the wound areas was performed on the different day and then percentage of wound closures were measured consequently. By the 14th day, silver nanoparticle gel showed $96.20 \%$ wound healing activity compared with that of the standard as well as control base.

The antibacterial inhibitory efficiency of prepared nano gel was found similar to the commercial product against the Staphylococcus aureus, E. coli and Pseudomonas aeruginosa. ${ }^{55}$ Wound healing activity of aqueous extract of holy basil leaves along with its effect on tumor necrosis factor-alpha was evaluated using excision model of wound repair. After application of the holy basil extract, rate of epithelization with an increase in wound contraction was observed. In animals, treated with $10 \%$ extract in petroleum jelly, wound healing was faster as compared to control group which were treated with petroleum jelly alone. ${ }^{56}$

\section{Radioprotective effect}

Vicenin-2 is a flavonoid collected from holy basil and it has been described to have radioprotective, anticancer, and radiosensitizing properties. Study evaluated the effect of Vicenin- 2 on the cell viability and the effect on PTEN and Akt1 when Vicenin-2 was used alone and in combination with radiation. It was reported that Vicenin-2 was able to lower cancer cell survival and phosphorylated Akt whereas promoting the expression of pro-apoptotic genes and decreasing antiapoptotic genes. ${ }^{57}$

Protective effect of two water-soluble flavonoids i.e., Orientin and Vicenin, isolated from the leaves of holy basil against radiation induced chromosome damage in cultured human peripheral lymphocytes was evaluated. Result confirmed that pre-treatment with either Orientin and Vicenin, at all concentrations significantly reduced the micronucleus count in a concentration dependent manner. Pre-treatment with Orientin or Vicenin significantly reduced the MN counts to $51-67 \% .^{58}$

A recent study was conducted to evaluate if holy basil protects against radiation induced lipid peroxidation in liver and to determine the role, if any, of the inherent antioxidant system in radioprotection by Ocimum sanctum. Ocimum sanctum, itself increased the GSH and enzymes significantly above normal levels whereas radiation significantly reduced all the values. Pretreatment with the extract checked the radiation induced depletion of GSH and all the enzymes and maintained their levels within or above the control range. Radiation significantly increased the lipid peroxidation rate after exposure. Extract pretreatment significantly reduced the lipid peroxidation and accelerated recovery to normal levels..$^{59}$

\section{Anti-cancer effect}

Natural products or active compound of medicinal plants play a vital role in disease management including cancer through modulating various biological activities. ${ }^{60-69}$ An important study based on colon cancer was conducted to analyse the anti-proliferative effect of Vicenin-2, a component of Ocimum sanctum on human colon cancer cells. Vicenin-2 is a flavonoid from basil and result of the study demonstrated that Vincenin-2 caused substantial cell cycle arrest at the $\mathrm{G}_{2} \mathrm{M}$ phase. Additionally, Vicenin-2 treatment increased the expression of cytochrome $\mathrm{C}$, Bax as well as caspase- 3 and decreased the expression of Bcl-2.70

Another study was performed to define the efficacy of vicenin-2, an active constituent of holy basil, as a single agent and in combination with docetaxel in carcinoma of prostate. Result demonstrated that vicenin-2 efficiently induced anti-proliferative, anti-angiogenic as well as pro-apoptotic. In this respect, vicenin-2 in combination with docetaxel synergistically inhibited the growth of prostate tumors. Based on finding, the study concluded e that vicenin-2 is effective against prostate cancer progression and indicated that vicenin-2 and docetaxel co-administration is more powerful than either of the single agents in androgen-independent prostate cancer. ${ }^{71}$ Vicenin-2 either in single form or in combination with radiation reduced the surviving cancer cells.

In addition, it increased DNA fragmentation and increased caspase- 3 activity and decreased levels of MMP-2 as well as $\mathrm{p} 21$ proteins. ${ }^{57}$ Ethanol extracts of holy basil showed anti-metastatic activity through activation of anti-oxidative enzymes. Extract caused cytotoxicity against lung carcinoma cells and significantly inhibited cell adhesion and invasion as well as activities of matrix metalloproteinase-9. Moreover, extract significantly reduced the tumor nodule formation, lung weight and inhibitory effect of extract on metastasis was confirmed. ${ }^{72}$

\section{CONCLUSION}

Medicinal plants and their products have been reported to offer protection against different diseases and have been used by traditional medical practitioners in their daily practice for the treatment and prevention of various diseases. In modern complementary and alternative medical practice, plants are the chief source of therapeutics and various parts of the plant, such as seeds, root, stem, leaves, as well as fruit holds various types of bioactive components. Holy basil has been shown to have a significant therapeutic role through modulating various biological activities. Holy basil holds various types of constituents and such ingredients play role in diseases cure. Various kinds of phytochemicals like flavonoids, phenolic compounds, saponins etc., are reported to be present in Tulsi that are supposed to be responsible for various biological activities of tulsi including antioxidant, anticancer, anti-microbial, anti-inflammatory, wound healing, cardioprotective effects. Howecer, antioxidant and antimicrobial properties of basil make it a potential source of antimicrobial and antioxidant agents. The natural products obtained from Tulsi are expected to serve as promising new pharmaceutical leads or dietary supplements to combat various diseases, and thus, they provide an explanation for the use of Tulsi in traditional medicines. Further, the holy basil receiving much attention of researcher/clinicians as its role in cancer prevention and treatment. Laboratory research confirmed that holy basil shows role in the inhibition of cancer. Details study should be performed to evaluate the mechanism of action in diseases management. 


\section{REFERENCES}

1. Jiang W Jiang B, Mantr N, Wu Z, Mao L, Lu H, Tao Z. Comparative ecophysiological analysis of photosynthesis, biomass allocation, polysaccharide and alkaloid content in three Dendrobium candidum cultivars. Plant Omics J. 2014;7:117-22.

2. Mandave P, Pawar P, Ranjekar P, Mantri N, Kuvalekar A. Comprehensive evaluation of in vitro antioxidant activity, total phenols and chemical profiles of two commercially important strawberry varieties. SciHortic. 2014;172:124-34.

3. Sun X, Mantri N, Ge J, Du Y, Wang G, Lu J, et al. Inhibition of plant pathogens in vitro and in vivo with essential oil and organic extracts of Torreya grandis "Merrilli' aril. Plant OMICS. 2014;7:337-44

4. Carović-Stanko K, Petek M, Grdiša M, Pintar J, Bedeković D, Herak Ćustić M, et al. Medicinal plants of the family Lamiaceae as functional foods - a review. Czech J Food Sci. 34;2016 (5):377-90.

5. Lal S, Mistary KN, Thaker N, Shah SD, Vaidya PB. Genetic diversity assessment in six medicinally important species of ocimumfrom central gujarat (india) utilizing RAPD, ISSR AND SSR markers. I J B R. 2012;2(2):279-88.

6. Pattanayak P, Behera P, Das D, Panda SK. Ocimum sanctum Linn. A reservoir plant for therapeutic applications: An overview. Pharmacogn Rev.2010;4(7):95105.

7. Biswas NP, Biswas AK. Evaluation of some leaf dusts as grain protectant against rice weevil Sitophilus oryzae (Linn.). Environ Ecol. 2005;23:485-8.

8. Eshrat Halim MA, Hussain, KJ, Rao M. Hypoglycaemic, hypolipidemic and antioxidant properties of tulsi (Ocimum sanctum linn) on streptozotocin induced diabetes in rats. Indian J Clin Biochem. 2001;16(2):190-4.

9. Yamani HA, Pang EC, Mantri N, Deighton MA. Antimicrobial Activity of Tulsi (Ocimum tenuiflorum) Essential Oil and Their Major Constituents against Three Species of Bacteria. Front Microbiol. 2016;7:681.

10. Karthikeyan K, Gunasekaran P, Ramamurthy N, Govindasamy S. Anticancer activity of Ocimum sanctum. Pharmac Biol. 1999;37:285-90.

11. Kelm MA, Nair MG, Strasburg GM, DeWitt DL. Antioxidant and cyclooxygenase inhibitory phenolic compounds from Ocimum sanctum Linn. Phytomedicine. 2000;7:7-13.

12. Jaggi RK, Madaan R, Singh B. Anticonvulsant potential of holy basil, Ocimum sanctum Linn., and its cultures. Indian J Exp Biol. 2003;41:1329-33.

13. Ganasoundari A, Uma devi P, Rao BS. Enhancement of bone marrow radiation protection and reduction in WR-2721 toxicity by Ocimum sanctum. MutatRes. 1998;373:271-5.

14. Keshari A, KSrivastava A, Verma AK, Srivastava R. Free radicals scavenging and protein protective property of Ocimum sanctum (L). British Journal of Pharmaceutical Research. 2016;14:1-10.

15. Choudhury SS, Bashyam L, Manthapuram N, Bitla P, Kollipara P, et al. Ocimum sanctum leaf extracts attenuate human monocytic (THP-1) cell activation. J Ethnopharmacol. 2014;154(1):148-55.

16. Manaharan T, Thirugnanasampandan R, Jayakumar R, Ramya G, Ramnath G, Kanthimathi MS, Antimetastatic and anti-inflammatory potentials of essential oil from edible Ocimum sanctum leaves. Sci World J. 2014;2014

17. Shokeen $P$, Bala $M$, Sing $M$, Tandon V. In vitro activity of eugenol, an active component from Ocimum sanctum, against multiresistant and susceptible strains of Neisseria gonorrhea. Int J Antimicrob Agents. 2008;32:172-9.

18. ShimizuT, Torres MP, Chakraborty S, Souchek JJ, Rachagani S, Kaur S, et al. Holy Basil leaf extract decreases tumorigenicity and metastasis of aggressive human pancreatic cancer cells in vitro and in vivo: potential role in therapy. Cancer Lett. 2013;336(2):270-80.

19. Ponnusam Y, Louis T, Madhavachandran V, Kumar S, Thoprani N, Hamblin MR, et al. Antioxidant Activity of The Ancient Herb, Holy Basil in $\mathrm{CCl}_{4}$-Induced Liver Injury in Rats. Ayurvedic. 2015;2(2):34-8.

20. Devi PU, Ganasoundari A. Modulation of glutathione and antioxidant enzymes by Ocimum sanctum and its role in protection against radiation injury. Indian $\mathrm{J}$ Exp Biol. 1999;37(3):262-8.

21. Shetty S, Udupa S, Udupa L. Evaluation of Antioxidant and Wound Healing Effects of Alcoholic and Aqueous Extract of Ocimum sanctum Linn in Rats. Evid Based Complement Alternat Med. 2008;5(1):95-101.

22. Manaharan T, Thirugnanasampandan R, Jayakumar R, Ramya G, Ramnath G, Kanthimathi MS. Antimetastatic and anti-inflammatory potentials of essential oil from edible Ocimum sanctum leaves. Sci World J. 2014;2014:239508

23. Singh S, Majumdar DK, Rehan HM. Evaluation of anti-inflammatory potential of fixed oil of Ocimum sanctum (Holybasil) and its possible mechanism of action. J Ethnopharmacol. 1996;54(1):19-26.

24. Ahmad A, Abuzinadah MF, Alkreathy HM, Banaganapalli B, Mujeeb M. Ursolic acid rich Ocimum sanctum $L$ leaf extract loaded nanostructured lipid carriers ameliorate adjuvant induced arthritis in rats by inhibition of COX-1, COX-2, TNF- $\alpha$ and IL-1: Pharmacological and docking studies. PLoS One. 2018;13(3):e0193451
25. Navin M, Ajay L, Naseem S, Seema S, Surendra S, Isha N. Preliminary ex-vivo and an animal model evaluation of Ocimum sanctum's essential oil extract for its antibacterial and anti- inflammatory properties. Oral Health Dent Manag. 2013;12(3):174-9.

26. Godhwani S, Godhwani JL, Vyas DS. Ocimum sanctum: an experimental study evaluating its anti-inflammatory, analgesic and antipyretic activity in animals. $J$ Ethnopharmacol. 1987;21(2):153-63.

27. Singh S, Majumdar DK. Evaluation of antiinflammatory activity of fatty acids of Ocimum sanctum fixed oil. Indian J Exp Biol. 1997;35(4):380-3.

28. Ghoke SS, Sood R, Kumar N. Evaluation of antiviral activity of Ocimum sanctum and Acacia arabica leaves extracts against H9N2 virus using embryonated chicken egg model. BMC Complement Altern Med. 2018;18(1):174.

29. Jayanti I, Jalaluddin M, Avijeeta A, Ramanna PK, Rai PM, Nair RA. In vitroAntimicrobial Activity of Ocimum sanctum (Tulsi) Extract on Aggregatibacter actinomycetemcomitans and Porphyromonas gingivalis. J Contemp Dent Pract. 2018;19(4):415-9.

30. Mallikarjun S, Rao A, Rajesh G, Shenoy R, Pai M. Antimicrobial efficacy of Tulsi leaf (Ocimum sanctum) extract on periodontal pathogens: An in vitro study. $J$ Indian Soc Periodontol. 2016;20(2):145-50.

31. Eswar P, Devaraj CG, Agarwal P. Anti-microbial Activity of Tulsi \{Ocimum Sanctum (Linn.)\} Extract on a Periodontal Pathogen in Human Dental Plaque: An In vitro Study. J Clin Diagn Res. 2016;10(3):ZC53-6.

32. Balakumar S, Rajan S, ThirunalasundariT, Jeeva S. Antifungal activity of Ocimum sanctum Linn. (Lamiaceae) on clinically isolated dermatophytic fungi. Asian Pac J Trop Med. 2011;4(8):654-7.

33. Patil R, Patil R, Ahirwar B, Ahirwar D. Isolation and characterization of antidiabetic component (bioactivity-guided fractionation) from Ocimum sanctum $\mathrm{L}$. (Lamiaceae) aerial part. Asian Pac J Trop Med. 2011;4(4):278-82.

34. Malapermal V, Botha I, Krishna SBN, Mbatha JN. Enhancing antidiabetic and antimicrobial performance of Ocimum basilicum, and Ocimum sanctum (L.) using silver nanoparticles. Saudi J Biol Sci. 2017;24(6):1294-305.

35. Suanarunsawat T, Anantasomboon G, Piewbang C. Anti-diabetic and antioxidative activity of fixed oil extracted from Ocimum sanctum L. leaves in diabetic rats. Exp Ther Med. 2016;11(3):832-40.

36. Vats V, Yadav SP, Grover JK. Ethanolic extract of Ocimum sanctum leaves partially attenuates streptozotocin-induced alterations in glycogen content and carbohydrate metabolism in rats. J Ethnopharmacol. 2004;90(1):155-60.

37. Chattopadhyay RR. Hypoglycemic effect of Ocimum sanctum leaf extract in normal and streptozotocin diabetic rats. Indian J Exp Biol. 1993;31(11):891-3.

38. Lahon K, Das S. Hepatoprotective activity of Ocimum sanctum alcoholic leaf extract against paracetamol-induced liver damage in Albino rats. Pharmacognosy Res. 2011;3(1):13 - 8.

39. Shah K, Verma RJ. Protection against butyl p-hydroxybenzoic acid induced oxidative stress by Ocimum sanctum extract in mice liver. Acta Pol Pharm. 2012;69(5):865 - 70.

40. Dharmani P, Kuchibhotla VK, Maurya R, Srivastava S, Sharma S, Palit G. Evaluation of anti-ulcerogenic and ulcer-healing properties of Ocimum sanctum Linn. J Ethnopharmacol. 2004;93(2-3):197-206.

41. Mandal S, Das DN, De K. Ocimum sanctum Linn--a study on gastric ulceration and gastric secretion in rats. Indian J Physiol Pharmacol. 1993;37(1):91-2.

42. Ahmed M, Ahamed RN, Aladakatti RH, Ghosesawar MG. Reversible anti-fertility effect of benzene extract of Ocimum sanctum leaves on sperm parameters and fructose content in rats. J Basic Clin Physiol Pharmacol. 2002;13(1):51-9.

43. Jothie Richard E, Illuri R, Bethapudi B. Anti-stress Activity of Ocimum sanctum: Possible Effects on Hypothalamic-Pituitary-Adrenal Axis. Phytother Res. 2016;30(5):805-14.

44. Singh V, Kahol A, Singh IP, Saraf I, Shri R. Evaluation of anti-amnesic effect of extracts of selected Ocimum species using in-vitro and in-vivo models. J Ethnopharmacol. 2016;193:490-9

45. Siddique $\mathrm{YH}$, Faisal M, Naz F, Jyoti $\mathrm{S}$, Rahul. Role of Ocimum sanctum leaf extract on dietary supplementation in the transgenic Drosophila model of Parkinson's disease. Chin J Nat Med. 2014;12(10):777-81.

46. Sembulingam $K$, Sembulingam $P$, Namasivayam A. Effect of Ocimum sanctum Linn on the changes in central cholinergic system induced by acute noise stress. J Ethnopharmacol. 2005;96(3):477-82.

47. Mukherjee R, Dash PK, Ram GC. Immunotherapeutic potential of Ocimum sanctum (L) in bovine subclinical mastitis. Res Vet Sci. 2005;79(1):37-43.

48. Mondal S, Varma S, Bamola VD. Double-blinded randomized controlled trial for immunomodulatory effects of Tulsi (Ocimum sanctum Linn.) leaf extract on healthy volunteers. J Ethnopharmacol. 2011;136(3):452-6.

49. Mediratta PK, Sharma KK, Singh S. Evaluation of immunomodulatory potential of Ocimum sanctum seed oil and its possible mechanism of action. J Ethnopharmacol. 2002;80(1):15-20. 
50. Sarkar A, Lavania SC, Pandey DN, Pant MC. Changes in the blood lipid profile after administration of Ocimum sanctum (Tulsi) leaves in the normal albino rabbits. Indian J Physiol Pharmacol. 1994;38(4):311-2.

51. Suanarunsawat T, Boonnak T, Na Ayutthaya WD, Thirawarapan S. Antihyperlipidemic and cardioprotective effects of Ocimum sanctum L. fixed oil in rats fed a high fat diet. J Basic Clin Physiol Pharmacol. 2010;21(4):387-400.

52. Meghwani $H$, Prabhakar $P$, Mohammed SA. Beneficial Effect of Ocimum sanctum (Linn) against Monocrotaline-Induced Pulmonary Hypertension in Rats. Medicines (Basel). 2018;5(2):34.

53. Kavitha S, John F, Indira M. Amelioration of inflammation by phenolic rich methanolic extract of Ocimum sanctum Linn. leaves in isoproterenol induced myocardial infarction. Indian J Exp Biol. 2015;53(10):632-40.

54. Udupa SL, Shetty S, Udupa AL, Somayaji SN. Effect of Ocimum sanctum Linn. on normal and dexamethasone suppressed wound healing. Indian J Exp Biol. 2006;44(1):49 - 54

55. Sood R, Chopra DS. Optimization of reaction conditions to fabricate Ocimum sanctum synthesized silver nanoparticles and its application to nano-ge systems for burn wounds. Mater Sci Eng C Mater Biol Appl. 2018;92:575 - 89.

56. Goel A, Kumar S, Singh DK, Bhatia AK. Wound healing potential of Ocimum sanctum Linn. with induction of tumor necrosis factor-alpha. Indian J Exp Biol. 2010;48(4):402-6

57. Baruah TJ, Kma L. Vicenin-2 acts as a radiosensitizer of the non-small cell lung cancer by lowering Akt expression. Biofactors. 2019;45(2):200-10.

58. Vrinda B, Uma Devi P. Radiation protection of human lymphocyte chromosomes in vitro by orientin and vicenin. Mutat Res. 2001;498(1-2):39-46.

59. Devi PU, Ganasoundari A. Modulation of glutathione and antioxidant enzymes by Ocimum sanctum and its role in protection against radiation injury. Indian $\mathrm{J}$ Exp Biol. 1999;37(3):262-8.

60. Rahmani AH, Alzohairy MA, Khan MA, Aly SM. Therapeutic Implications of Black Seed and Its Constituent Thymoquinone in the Prevention of Cancer through Inactivation and Activation of Molecular Pathways. Evid Based Complement Alternat Med. 2014;2014:724658.

61. Almatroudi A, Alsahli MA, Alrumaihi F, Allemailem KS, Rahmani AH. Ginger: A Novel Strategy to Battle Cancer through Modulating Cell Signalling Pathways: A Review. Curr Pharm Biotechnol. 2019; 20:5-16.
62. Rahmani AH, Aldebasi YH, Srikar S, Khan AA, Aly SM. Aloe vera: Potential candidate in health management via modulation of biological activities. Pharmacogn Rev 2015;9:120-6.

63. Rahmani AH, Al Shabrmi FM, Allemailem KS, Aly SM, Khan MA. Implications of green tea and its constituents in the prevention of cancer via the modulation of cell signalling pathway. BioMed Res Int. 2015;2015:925640.

64. Rahmani AH, Alsahli MA, Aly SM.; Khan MA, Aldebasi YH. Role of curcumin in disease prevention and treatment. Adv Biomed Res 2018;7:38.

65. Almatroodi SA, Alsahli MA, Almatroudi A, Rahmani AH. Garlic and its active compounds: a potential candidate in the prevention of cancer by modulating various cell signalling pathways. Anticancer Agents Med Chem. 2019;19(11):1314-24

66. Rahmani A, Alsahli M, Almatroodi S. Active constituents of pomegranates (Punicagranatum) as potential candidates in the management of health through modulation of biological activities. J Pharmacogn. 2017;9(5):689-95.

67. Almatroodi SA, Alrumaihi F, Alsahli MA, Alhommrani MF, Khan A, Rahman $\mathrm{AH}$. Curcumin, an Active Constituent of Turmeric Spice: Implication in the Prevention of Lung Injury Induced by Benzo(a) Pyrene (BaP) in Rats. Molecules. 2020;25:724.

68. Almatroodi SA, Alsahli MA, Alharbi HM, Khan AA, Husain Rahmani A Epigallocatechin-3-Gallate (EGCG), An Active Constituent of Green Tea: Implications in the Prevention of Liver Injury Induced by Diethylnitrosamine (DEN) in Rats. Appl Sci. 2019;4:4821.

69. Rahmani AH, Almatroudi A, AlRumaihi F, Khan AA. Pharmacological and therapeutic potential of neem (Azadirachta indica). Pharmacogn Rev. 2018;12:250.

70. Yang $D$, Zhang $X$, Zhang $W$, Rengarajan T. Vicenin-2 inhibits Wnt/ $/$-catenin signaling and induces apoptosis in HT-29 human colon cancer cell line. Drug Des Devel Ther. 2018;12:1303-10.

71. Nagaprashantha LD, Vatsyayan R, Singhal J. Anti-cancer effects of nove flavonoid vicenin-2 as a single agent and in synergistic combination with docetaxel in prostate cancer. Biochem Pharmacol. 2011;82(9):1100-9.

72. Kim SC, Magesh V, Jeong SJ. Ethanol extract of Ocimum sanctum exerts anti-metastatic activity through inactivation of matrix metalloproteinase- 9 and enhancement of anti-oxidant enzymes. Food Chem Toxicol. 2010;48(6):1478-82.

\section{GRAPHICAL ABSTRACT}

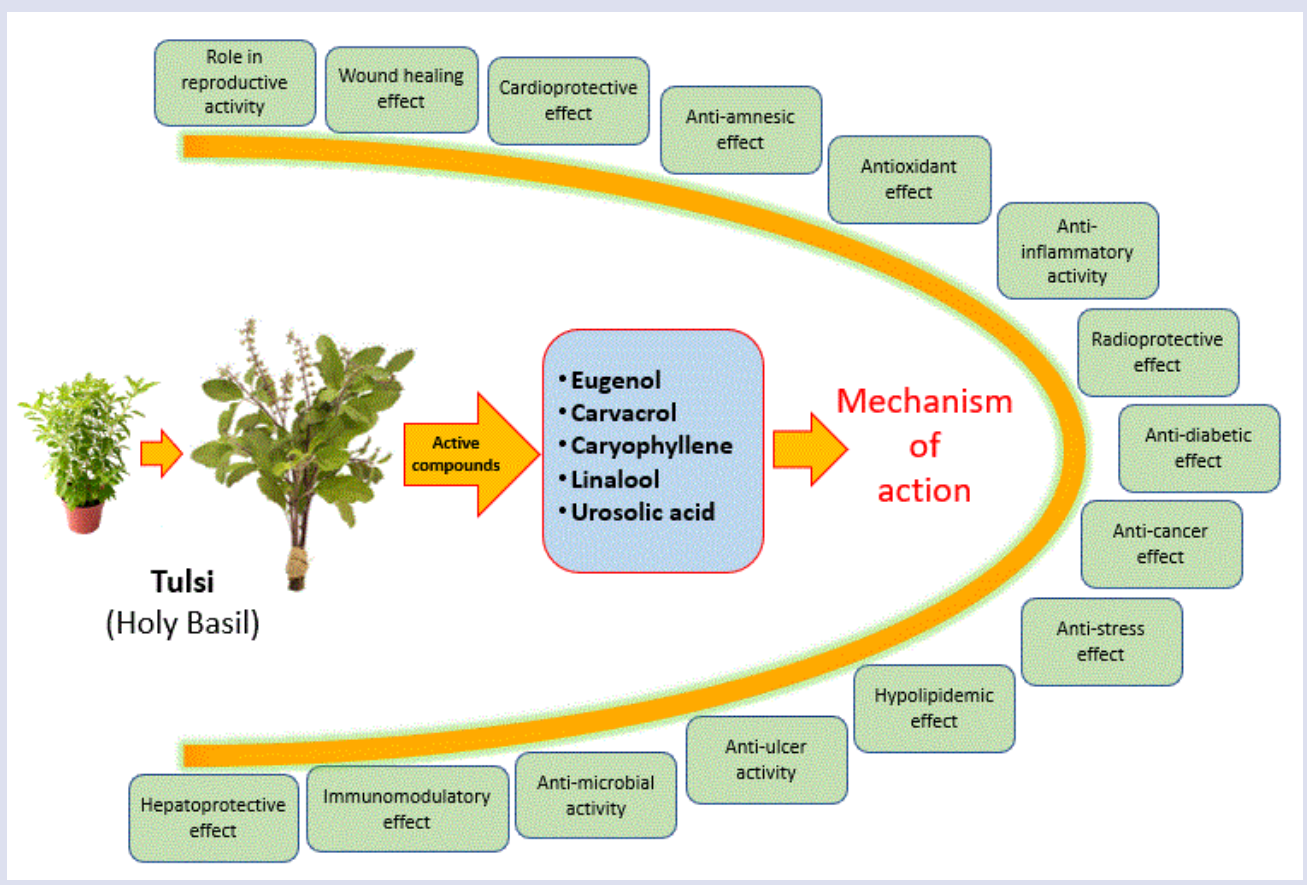




\section{ABOUT AUTHORS}

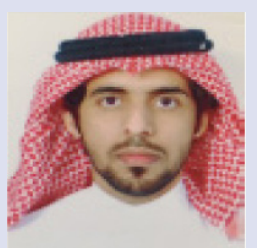

Saleh A. Almatroodi: Is a researcher and an assistant professor in laboratory medicine at Qassim University. He is the Vice Dean of College of Applied Medical Science and the head of E-learning unit in College of Applied Medical Sciences, Qassim University, Kingdom of Saudi Arabia. His research interests include evaluation of the therapeutic potential of natural compounds in the management of diseases including cancer. He has published several meaningful research papers in international repute journal and has presented his papers in many national and international conferences.

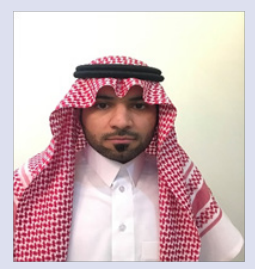

Ahmad Almatroudi Is working as an Assistant Professor in the Department of Medical Laboratories, College of Applied Medical Sciences, Qassim University, Kingdom of Saudi Arabia. His research interests include measurement of the therapeutic potential of natural compounds in the management of diseases, Public health and Microbiology. Ahmad Almatroudi is currently chairman of Department of Medical Laboratories. He has published several meaningful research and review article, of international repute journal and has presented his papers in many national and international conferences.

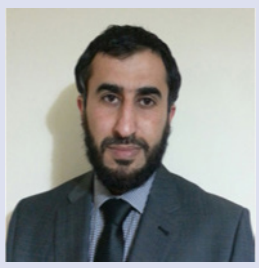

Mohammed A. Alsahli: Is an Assistant Professor in Medical Laboratory Sciences at Qassim University. His research interests involve medical laboratory sciences in general, particularly oncology, platelet biology and haemostatic regulation in prothrombotic diseases. Mohammed is currently the Dean of College of Applied Medical Sciences, Qassim University, Saudi Arabia. He has published several research and review article, of international repute journal.

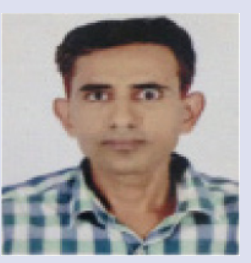

Arshad Husain Rahmani: Is working as an Assistant Professor in the Department of Medical Laboratories, College of Applied Medical Sciences, Qassim University, Kingdom of Saudi Arabia. His research interests include measurement of the therapeutic potential of natural compounds in the management of diseases and expression pattern of the genes linked to cancer development and progression. He has published more than 70 research and review article, of international repute. Besides this, he is an active reviewer of several ISI indexed journals.

Cite this article: Almatroodi SA, Alsahli MA, Almatroudi A, Rahmani AH. Ocimum sanctum: Role in Diseases Management Through Modulating Various Biological Activity. Pharmacogn J. 2020;12(5):1198-205. 